\title{
Repetitive stimulation of the long thoracic nerve in myasthenia gravis: clinical and electrophysiological correlations
}

\author{
Y L Lo, T H Leoh, Y F Dan, Y E Tan, S Nurjannah, P Ratnagopal
}

Objective: To investigate repetitive stimulation of the long thoracic nerve as a reliable and technically undemanding method for evaluating respiratory muscle function in myasthenia gravis.

Methods: 15 patients with myasthenia gravis and positive single fibre electromyography had repetitive stimulation of the long thoracic nerve together with serratus anterior recordings. There were 20 normal controls.

Results: Eight patients with respiratory symptoms all had abnormal results, with an increased response decrement. These patients required intensive monitoring and supplemental oxygen. The remaining seven cases with no respiratory symptoms all had negative studies.

Conclusions: This is a simple well tolerated method that shows good correlation with respiratory symtoms and management requirements in myasthenia gravis. It can alert the physician to serious respiratory complications in this disease.

n n myasthenia gravis, respiratory and bulbar weakness are major concerns of the attending physician. Respiratory failure is a potentially reversible complication, and prompt specific treatment can prevent its onset. ${ }^{12}$ However, reliable noninvasive assessment of respiratory muscle function in myasthenia gravis can be difficult in view of the inherent problems of facial weakness, effort related changes, and artefacts. A previous study employing repetitive phrenic nerve stimulation found a poor correlation with respiratory symptoms. In our experience, repetitive phrenic nerve stimulation can be technically challenging, particularly in obese subjects with a low pain tolerance. In the present study, we evaluated the use of repetitive long thoracic nerve stimulation using serratus anterior recordings. Our aim was to find an alternative, reliable, and technically less challenging method for evaluating respiratory muscle function in myasthenia gravis.

\section{METHODS}

We carried out a prospective study on 15 consecutive patients referred for electrophysiological assessment of myasthenia gravis over a nine month period. Most had been admitted for hospital treatment. Twenty normal controls were studied for comparison, with their informed consent.

All patients had stimulated single fibre electromyography (SFEMG) of the orbicularis oculi and repetitive nerve stimulation using nasalis, trapezius, and abductor pollicis recordings.

For SFEMG studies (done by YLL), the stimulation technique employed a Teca disposable monopolar needle (Teca Co, Old Woking, Surrey, UK) placed $3 \mathrm{~cm}$ away from the edge of the orbicularis oculi. Stimulation pulses of $0.01 \mathrm{~ms}$ at $10 \mathrm{~Hz}$ and 5 to $12 \mathrm{~mA}$ were given. A Dantec $40 \mathrm{~mm}$ 13K87 needle (Dantec Co, Skovlunde, Denmark) was inserted at the edge of the muscle for single fibre recordings. The amplifier frequency range setting was 500 to $10 \mathrm{kHz}$. Single fibre responses were selected on the basis of short rise times $(<300 \mu \mathrm{s})$, clear separation from other discharges, and a stable waveform. Mean jitter was calculated from 20 acceptable single fibre responses. ${ }^{4}$ All SFEMG studies were carried out on a Dantec Keypoint EMG machine. Based on our laboratory normal values, the upper limit for mean jitter was $23 \mu$ s.

Repetitive nerve stimulation was undertaken by a member of the technical staff blinded to the clinical features of each patient. Surface stimulation and recordings were made with Medtronic 9013S0241 disposable adhesive electrodes (Medtronic Co, Skovlunde, Denmark). Studies were done using a Dantec Keypoint EMG machine with amplifier filter frequencies set at 10 to $5 \mathrm{kHz}$. Ten single square wave pulses of $0.3 \mathrm{~ms}$ duration at $3 \mathrm{~Hz}$ were used for each stimulation run. Surface temperature was kept at $32^{\circ}$ to $34^{\circ} \mathrm{C}$. Automated decrement calculation of baseline to negative peak amplitude between the first and fourth compound muscle action potential (CMAP) was recorded. Each patient and control had five runs for each muscle recording to obtain a final averaged decrement percentage. After the first stimulation run, the patient was instructed to maintain 15 seconds of maximal muscular contraction. Postexercise stimulation was done to exclude the presence of an incremental response.

Repetitive stimulation of the long thoracic was carried out with the patient in a comfortable supine position. A similar adhesive electrode was placed over the sixth rib at the mid-axillary line. The reference electrode was placed over the same rib medially at the anterior axillary line. Stimulations using Dantec 9013L0221 bipolar electrodes were made near Erb's point, lateral to the clavicular head of the sternomastoid. ${ }^{5}$ The electrodes were held firmly and directed posteriorly to avoid phrenic nerve stimulation. An assistant was present to steady the neck and ipsilateral arm. The subject was instructed to hold his breath in mid-expiration during stimulation.

Square wave pulses 0.2 to $0.3 \mathrm{~ms}$ duration at 15 to $25 \mathrm{~mA}$ were given to elicit supramaximal responses. Automated decrement calculations were made as for other muscles. The clinical and electrophysiological findings were correlated at the end of the study.

\section{RESULTS}

All patients and controls tolerated the procedure well. In the control group (mean age 49 years, range 15 to 76 ; 12 women, eight men), the mean (SD) latency for long thoracic nerve stimulation was 3.8 (0.32) ms. The mean amplitude was 2.7 $(1.1) \mathrm{mV}$. In the patient group (mean age 46 years, range 16 to 73; nine women, six men), the mean latency and amplitudes 
Table 1 Summary of clinical and electrophysiological features of the patients with myasthenia gravis

\begin{tabular}{|c|c|c|c|c|c|c|c|c|}
\hline Case & $\begin{array}{l}\text { Age } \\
\text { (years) }\end{array}$ & Sex & SFEMG & $\begin{array}{l}\text { RNS } \\
\text { decrement }\end{array}$ & $\begin{array}{l}\text { RNS SA } \\
(\%)\end{array}$ & Symptoms & CT scan & Outcome \\
\hline 1 & 48 & $\mathrm{~F}$ & + & - & -12 & $D, O, E, W$ & Thymoma & 1 \\
\hline 2 & 30 & $\mathrm{~F}$ & + & NA, TR & -6 & $P, W$ & Thymoma & $S$ \\
\hline 3 & 63 & $M$ & + & NA, TR & -35 & $D, E, P$ & - & 1 \\
\hline 4 & 34 & $M$ & + & NA, TR, APB & -30 & $D, O, E, W$ & Thymoma & $\mathrm{I}, \mathrm{V}$ \\
\hline 5 & 42 & $M$ & + & - & -4 & Dysarthria & - & S \\
\hline 6 & 68 & $M$ & + & - & -11 & $D, E, W$ & $\mathrm{TH}$ & I \\
\hline 7 & 71 & $\mathrm{~F}$ & + & - & -27 & $D, E$ & Thymoma & 1 \\
\hline 8 & 34 & $M$ & + & NA, TR & -79 & $D, O, E, W$ & Thymoma & I, V \\
\hline 9 & 46 & $\mathrm{~F}$ & + & - & -5 & $\mathrm{P}$ & - & S \\
\hline 10 & 50 & $\mathrm{~F}$ & + & - & -4 & P & - & $\mathrm{S}$ \\
\hline 11 & 39 & $\mathrm{~F}$ & + & $N A, A P B$ & -36 & $D, E, W$ & $\mathrm{TH}$ & I \\
\hline 12 & 16 & $\mathrm{~F}$ & + & NA, TR & -35 & $D, E, W, P$ & Thymoma & i \\
\hline 13 & 73 & $\mathrm{~F}$ & + & - & -5 & Diplopia & - & $S$ \\
\hline 14 & 37 & $M$ & + & NA & -2 & $W, P$ & Thymoma & $\mathrm{S}$ \\
\hline 15 & 39 & $\mathrm{~F}$ & + & NA & -3 & Diplopia, P & - & $\mathrm{S}$ \\
\hline \multicolumn{9}{|c|}{$\begin{array}{l}\text { APD, abductor pollicis brevis recording; } C T \text {, computed tomography; } D \text {, dyspnoea; } E \text {, reduced effort } \\
\text { tolerance; } F \text {, female; I, intensive monitoring; } M \text {, male; NA, nasalis recording; } O \text {, orthopnoea; } P \text {, ptosis; RNS, } \\
\text { repetitive nerve stimulation; } S \text {, symptomatic treatment; SA, serratus anterior recording; SFEMG, single fibre } \\
\text { electromyography; TH, thymic hyperplasia; TR, trapezius recording; } V \text {, artificial ventilation; W, weakness; +, } \\
\text { positive; -, negative. }\end{array}$} \\
\hline
\end{tabular}
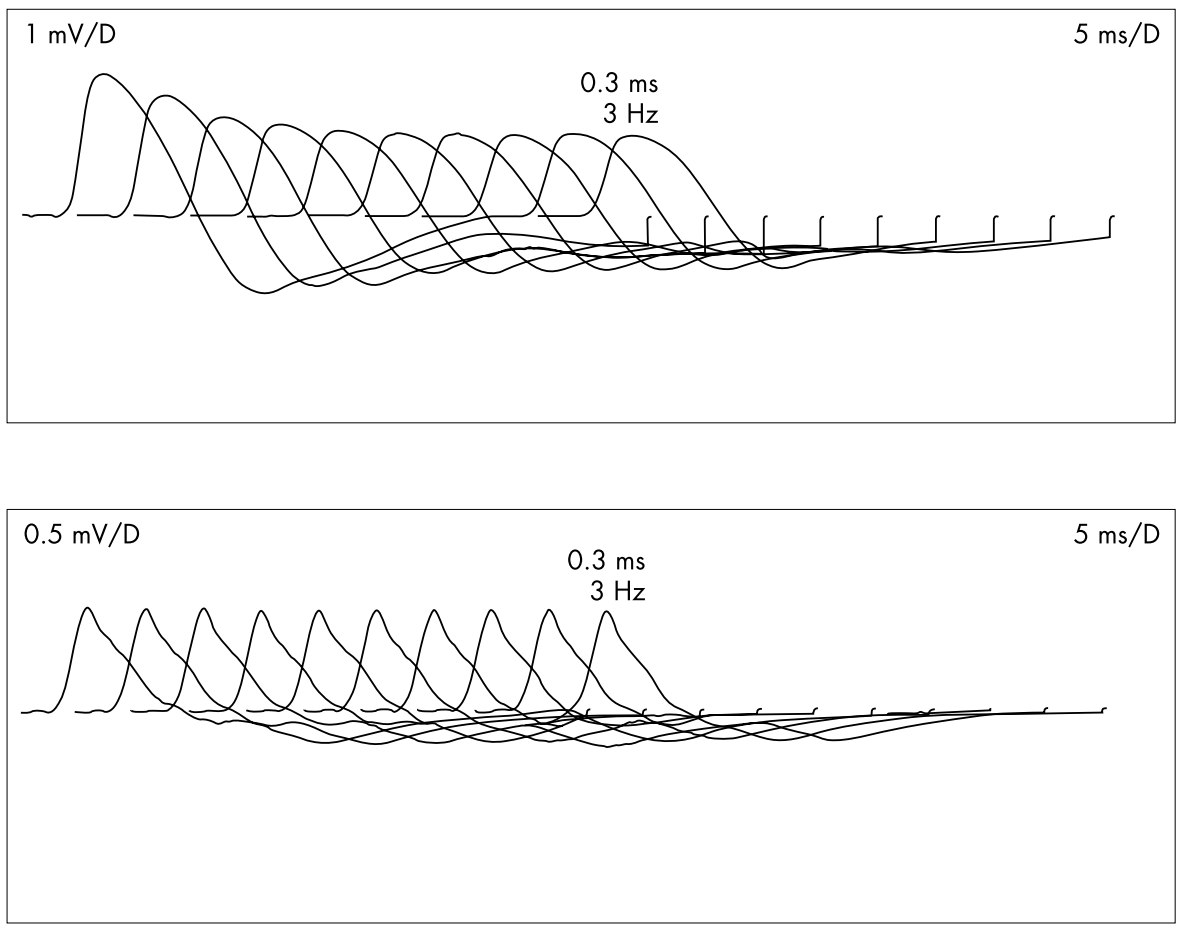

Figure 1 Serratus anterior recordings from repetitive long thoracic nerve stimulation in case 12 (top trace) and a normal control (bottom trace). Actual decrements were $-33 \%$ and $-4 \%$ respectively. Vertical gain and horizontal sweep are indicated in the tracings.

were $3.5(0.4) \mathrm{ms}$ and $2.6(1.2) \mathrm{mV}$, respectively. All patients had positive SFEMG studies.

In the control group, repetitive long thoracic nerve stimulation yielded a mean decrement of $-1.2(4.1) \%$. Thus a decrement of $-9.4 \%$ ( 2 SD) was chosen as the lower limit of normal. For other muscles, a repetitive nerve stimulation decrement above $-8 \%$ between the first and fourth negative peak amplitudes was considered abnormal. ${ }^{6}$

Eight patients had symptoms of dyspnoea, orthopnoea, and reduced effort tolerance. All these had abnormal repetitive long thoracic nerve stimulation. In three, this was the only abnormal finding among the repetitive nerve stimulation tests carried out. All eight cases needed intensive monitoring and supplemental oxygen. Cases 4 and 8 eventually required artificial ventilation. However, a forced vital capacity below 1 litre was documented in only six of these eight patients (cases 1, 3, $4,6,7$, and 8 ).

The remaining seven cases with no respiratory symptoms all had normal repetitive long thoracic nerve stimulation and only required symptomatic pharmacological treatment.

Acetylcholine receptor antibodies were positive in cases 2, 4, $8,11,12$, and 14 .

All the results are summarised in table 1. Figure 1 shows actual recordings in a patient and a normal control.

\section{DISCUSSION}

Though it has been used as a test of respiratory involvement in myasthenia gravis, repetitive stimulation of the phrenic nerve has several drawbacks, including poor patient intolerance, technical difficulties, pseudofacilitation, and ECG artefacts. ${ }^{3}$ 
The serratus anterior is regarded as an accessory muscle of respiration $^{7}$ and has also been shown to fatigue in myasthenia gravis because of impairment of neuromuscular transmission. ${ }^{8}$ In our experience, repetitive long thoracic nerve stimulation lacks the specific problems encountered in phrenic nerve stimulation, and this made it a suitable test for evaluation in our study.

The results of our long thoracic nerve conduction studies in the controls and the patients are comparable with those in a previous report. ${ }^{9}$ SFEMG, generally acknowledged as the most sensitive technique for studying neuromuscular transmission, ${ }^{10}{ }^{11}$ was used as the gold standard for comparison. It is, however, a more invasive, time consuming, and technically demanding method than repetitive nerve stimulation. The latter is a simple technique for demonstrating a neuromuscular transmission defect ${ }^{12}$ and is especially sensitive in proximal ${ }^{13}$ and clinically weak muscles. ${ }^{14} 15$

Seven of our 15 patients had a thymoma, and all of these either had generalised weakness or respiratory symptoms. Two eventually needed artificial ventilation. As in other series, the presence of a thymoma was associated with more severe disease and a worse outcome. ${ }^{16-18}$ In our experience, it is this group of patients in whom particular vigilance is needed in case they develop severe respiratory complications. The results of repetitive long thoracic nerve stimulation in our series showed a good correlation with respiratory symptoms and management requirements (respiratory function monitoring and support).

Various difficulties encountered in using respiratory function tests in myasthenia gravis include poor patient cooperation, facial muscle weakness, and lack of correlation with clinical status. ${ }^{19}$ However, early detection of respiratory compromise is important in the management of this disease. We have demonstrated a simple, well tolerated, and accurate method for this purpose and advocate its use in alerting the physician to the possibility of serious respiratory complications.

\section{Authors' affiliations}

Y L Lo, T H Leoh, Y F Dan, Y E Tan, S Nurjannah, P Ratnagopal, Department of Neurology, Singapore General Hospital, Singapore

Competing interests: none declared
Correspondence to: Dr Y L Lo, Department of Neurology, Singapore General Hospital, Outram Road, Singapore 169608; gnrlyl@sgh.com.sg

Received 7 August 2002

Accepted 2 December 2002

\section{REFERENCES}

1 Zulueta JJ, Fanburg BL, Respiratory dysfunction in myasthenia gravis. Clin Chest Med 1994;15:683-91.

2 Mier-Jedrzejowicz AK, Brophy C, Green M. Respiratory muscle function in myasthenia gravis. Am Rev Respir Dis 1988;138:867-73.

3 Zifko UA, Nicolle MW, Grisold W, et al. Repetitive phrenic nerve stimulation in myasthenia gravis. Neurology 1999;53:1083-7.

4 Schwartz MS, Stalberg E. Single fibre electromyographic studies in myasthenia gravis with repetitive nerve stimulation. J Neurol Neurosurg Psychiatry 1975;38:678-82

5 Cherington $\mathbf{M}$. Long thoracis nerve: conduction studies. Dis Nerv Syst 1972:33:49-51.

6 Desmedt JE. The neuromuscular disorder on myasthenia gravis. In: Desmedt JC, ed. New developments in electromyography and clinical neurophysiology. Basel: Karger, 1973:241-304.

7 Reid DC, Bowden J, Lynne-Davies P. Role of selected muscles of respiration as influenced by posture and tidal volume. Chest 1976:70:636-40.

8 Pagala M, Nandakumar NV, Venkatachari SA, et al. Mechanisms of fatigue in normal intercostal muscle and muscle from patients with myasthenia gravis. Muscle Nerve 1993;16:911-21.

9 Alfonsi E, Moglia A, Sandrini G, et al. Electrophysiological study of the long thoracic nerve conduction in normal subjects. Electromyogr Clin Neurophysiol 1986;26:63-67.

10 Padua L, Stalberg E, LoMonaco $M$, et al. SEMG in ocular myasthenia gravis. Clin Neurophysiol 2000;1 11:1203-7.

11 Sonoo $M$, Uesugi $H$, Mochizuki A, et al. Single fibre EMG and repetitive nerve stimulation of the same extensor digitorum communis muscle in myasthenia gravis. Clin Neurophysiol 2001;112:300-3.

12 Harvey AM, Masland RL. A method for the study of neuromuscular transmission in human subjects. Bull Johns Hopkins Hosp 1941;68:81-93

13 Krarup C. Electrical and mechanical responses on the platysma and adductor pollicis muscle in normal subjects. J Neurol Neurosurg Psychiatry 1977:40:234-40.

14 Jablecki CK. Electrodiagnostic evaluation of patients with myasthenia gravis and related disorders. Neurol Clin 1985;3:557-72.

15 Kennett RP, Fawcett PRW. Repetitive nerve stimulation of the anconeus in the assessment of neuromuscular transmission disorders. Electroencephalogr Clin Neurophysiol 1993;89:170-6.

16 Monden Y, Uyama T, Taniki T, et al. The characteristics of thymoma with myasthenia gravis: a 28-year experience. J Surg Oncol 1988;38:151-4

17 Palmisani MT, Evoli A, Batocchi AP, et al. Myasthenia gravis associated with thymoma: clinical characteristics and long-term outcome. Eur Neurol 1994;34:78-82.

18 Mantegazza R, Beghi E, Pareyson D, et al. A multicentre follow-up study of 1152 patients with myasthenia gravis in Italy. J Neurol 1990:237:339-44.

19 Evoli A, Batocchi AP, LoMonaco M, et al. Clinical heterogeneity of seronegative myasthenia gravis. Neuromuscul Disord 1996;6:155-61 